\title{
Política em poesia no avesso da publicidade: Uma leitura de Manuel de Freitas
}

\section{Politic in poetry in the reverse of merchandising: A reading of Manuel de Freitas}

\author{
Luis MAFFEI ${ }^{1}$ \\ Universidade Federal Fluminense (UFF)
}

RESUMO: Manuel de Freitas, destacado representante da poesia portuguesa recente, tem como um de seus mais frequentes problemas a tentativa de estabelecer em sua obra uma discussão de caráter público, que toque inclusive o papel do poeta numa contemporaneidade tão maciçamente avessa à linguagem poética. Certo poema de seu livro Game over, "Spot", tem como gatilho um comercial de televisão, e ataca a publicidade como uma atualização de antigos procedimentos autoritários. A leitura desse poema, considerado no universo da obra já consistente de seu jovem autor, permite uma frutífera discussão acerca do problema muito atual do acúmulo de linguagens e comunicações diversas, bem como a dicotômica relação entre poesia e publicidade.

PALAVRAS-CHAVE: Manuel de Freitas. Poesia portuguesa contemporânea. Política; publicidade.

ABSTRACT: Manuel de Freitas, important name of the recent Portuguese poetry, has as the one of its more frequent problems attempt to establish in its workmanship a discussion full of public character, that has also touched the role of the poet in a moment so massively antagonistic to the poetical language. Certain poem of its book Game over, "Spot", has as trigger a television spot, and attacks the advertising as an update of old authoritarian procedures. The reading of this poem, considered in the universe of the already consistent workmanship of its young author, allows to a fruitful discussion concerning the very current problem of the accumulation of languages and various communications, as well as the dichotomic relation between poetry and advertising.

\footnotetext{
${ }^{1}$ luismaffei@id.uff.br
} 
KEYWORDS: Manuel de Freitas. Portuguese contemporary poetry. Politics. Advertising

Cícero traduziu Politéia por res publica ao verter Platão ao latim. Digo isso apenas para pensar numa ideia de público que, tal como surge na boca do Sócrates que diz muita coisa n'A República, centra-se na "justiça" como bem indispensável à cidade, consequentemente aos cidadãos. Cidade é res publica, política não apenas é governo, é mais: é o que pertence à cidade, ao cidadão. Os brevíssimos e precários apontamentos que acabo de fazer são, além de brevíssimos e precários, óbvios, mas me servem para começar a perceber o que há num poeta e num específico poema que obrigam a pensar em coisas públicas:

"A vida não pode ser assim

tão assustadora",

diz a margarina becel

em horário nobre,

para não-cardíacos.

$\mathrm{O}$ que, na verdade, me

deixa saudades da censura,

de uma censura nova

que exterminasse imbecis

e deixasse a terra a quem

ela é, como deve ser, pesada.

(FREITAS, 2007, p. 55)

O poeta, Manuel de Freitas; o poema, "Spot", editado em Game over, livro de 2002. Freitas faz política na cidade desde seu livro de estreia, Todos contentes e eu também, de 2000, e intensifica, dois anos depois, sua tarefa, na organização de uma antologia por ele prefaciada, intitulada poetas sem qualidades. Não me deterei aqui na posição marcada pelo poeta no prefácio à antologia, sequer me deterei no prefácio, apenas digo que é um texto combativo. Um dos alvos do enfrentamento, a cultura; um dos vieses motivadores, expresso citando David Harvey (2006, p. 221) (mas poderia ser Fredric Jameson): “É inegável que 
a cultura se transformou em algum gênero de mercadoria". É inegável também a premência de refletirmos sobre que sociedade nos cerca, onde poetas com dicção política têm terreno fértil para denominarem-se sem qualidades. A propósito, uma das razões de eu não me deter no prefácio à famosa antologia é o fato de vários autores, eu inclusive ${ }^{2}$, já o terem feito, e a discussão em torno desse problema - que envolve herança e ruptura, rebeldia e encenação de rebeldia - estar tão bem encaminhada que tangencia a gagueira.

Meu assunto neste texto é uma poesia que se quer política, num tempo específico. Político não é apenas o partidário-eleitoral, mas também o é. Pensar em nosso mundo (em nosso tempo) politicamente é tarefa menos árdua se recolho certas ideias. Uma delas: "A criação da imagem dos políticos pelos meios de comunicação de massa para venda aos eleitores-consumidores [...] alimenta um imaginário político autoritário", de acordo com Marilena Chauí (2001, p.436). A "cultura se transformou em algum gênero de mercadoria”, os políticos se transformaram "em algum gênero de mercadoria", a política e a cidade, claro, se transformaram "em algum gênero de mercadoria". A "margarina becel" é uma "mercadoria", e detenho-me num verso nuclear de "Spot": "diz a margarina becel". É espantoso, justamente porque não é espantoso: uma "margarina" é capaz de dizer, de ter voz, no universo da publicidade.

Isso é tão mais espantoso quando pensamos, por exemplo, que a poesia feminina em Portugal tem como marco, por volta dos anos de 1960, uma fala erotizada que se assume no feminino e dita pelo feminino. Um exemplo são famosos versos de Luiza Neto Jorge: "falo/ com uma agulha de sangue/ a coser-me todo o corpo/ à garganta" (JORGE, 2001, p. 57). Nos anos 60 (Terra imóvel,

\footnotetext{
${ }^{2}$ Alguns desses vários autores: Rosa Martelo, António Guerreiro, Ida Alves e Fernando Pinto do Amaral. Em meu caso, o texto mais diretamente debruçado sobre esse problema intitula-se "Os poetas sem qualidades, em busca da contemporaneidade possível", e foi publicado na Revista de Letras da UNESP, v. 51, n. 2, de 2005 .
} 
recolha onde está o fragmento, é de 1964), época de revoluções ainda políticas e época de uma poesia, em Portugal, promotora da fecunda aliança entre revolver o verso e revoltar as mentes, "O poema" diz uma primeira pessoa no feminino que diz a fala e engole o falo. Dizer, portanto, é ter a voz, tomá-la, é índice de afirmação. Para que não fique a impressão de que o poema citado é excepcional e que o tema aparece apenas em autoras, dou outro exemplo: em "Duas pessoas", de Os passos em volta, de 1963, o narrador é um homem que chama a seu quarto uma prostituta, mas ele só é narrador até metade do texto; a partir de então, Herberto Helder (2010) dá voz a uma narradora, que acaba por se mostrar a voz mais inteligentemente analítica do conto.

A res publica hodierna é assim expressa por Eugênio Bucci: "[...] a sociedade em que vivemos [...] tem a sua esfera pública privatizada"; logo, "os atributos da cidadania se convertem em bens de consumo e [...] a lógica do espetáculo absorve e comanda a organização e a disposição dos conteúdos" (BUCCI, 2004, p. 41). Ou seja, se a esfera pública que se apresenta em textos como os de Luiza e Herberto dá voz a um problema que extrapola o privado, é porque a coletivização que se via na altura ainda permitia uma sugestão plural. Na mesma década, contudo, já havia, pois já os há desde o século XIX, sintomas que aparecem no pensamento de Guy Debord. O pensador francês ajuda-me a pensar responsavelmente certas questões contemporâneas, pois, num momento histórico crítico, levantou problemas que têm alta atualidade. Debord (1997), que, não tarda, será citado aqui, permitiu a Bucci (2004) referir-se à "lógica do espetáculo" como realidade dominante da "esfera pública", e o cidadão, ou seja, o indivíduo que habita a cidade e a constrói, vê-se em situação de ter de privatizar-se para existir. $O$ fato de muitas pessoas encontrarem-se excessivamente vinculadas a empresas privadas dá o que pensar, pois revela o quanto as marcas têm poder na construção atual das subjetividades.

Poetas ocupam espaços nada estratégicos nos dias de hoje. $\mathrm{Na}$ lírica portuguesa, é formuladamente marginal a posição de 
quem faz versos desde Cesário $V_{e r d e}^{3}$, desde, portanto, o fim do século XIX. Essa época, aliás, é central para a constituição do mundo como se apresenta hoje em dia, especialmente no tocante ao que importa a esse texto, e é imprescindível a leitura de Benjamin sobre Baudelaire, capaz de revelações como esta: "A ebriedade a que se entrega of flaneur é a da mercadoria em torno da qual brame a corrente dos fregueses" (BENJAMIN, 1989, p. 51). O poeta-flâneur não é mais o vate, ainda que Cesário seja um flâneur especial, pois passeia tanto pela cidade como pela história. No caso português, mesmo o vate por excelência disse contra, empreendendo severas críticas ao projeto expansionista. Portanto, portuguesamente, certa marginalidade toca a prática da poesia a partir, pelo menos, de Camões - não custa repetir que um dos mais extremos problemas camonianos foi a pobre recepção à sua arte e à alheia, "Porque, quem não sabe arte, não na estima" (Lus, V, 97, 8).

Problema dagora: poetas dizem, mas para quem? A "margarina becel" "diz", e para público vasto e obediente, para um público consumidor. Problema dagora: se mesmo os "eleitores" são "consumidores", mesmo o gesto público do voto torna-se privado, semelha-se a escolher um produto a partir duma propaganda de tevê. Mais que isso: "quem não sabe arte" pode se deslumbrar com a comunicação imediata e inteligível de um spot publicitário, e não perceber que esse tipo de comunicação possui uma gana de estima muito interessada e teleológica. Qual o télos em questão? Não é, e nem pode ser, desinteressado de objetivo presente em todo e qualquer contexto de convencimento consumidor: o ato do próprio consumo, a compra. Mais que isso, a elevação da marca ao estatuto de afetivo e efetivo sujeito de relação.

E como chamar, atualmente, o coração? A problemática a que me dedico tem que ver, não apenas com o lugar do poeta,

\footnotetext{
${ }^{3}$ Trato bem mais longamente do autor de "Sentimento dum ocidental" diante deste problema num ensaio intitulado "Cesário e uma cara de seu tempo (que não foi outra)", editado na revista Via Atlântica (USP), n. 15, de 2009.
} 
mas com sua identidade - digo de passagem, é mais fácil uma margarina dizer o coração que um poeta, pois, para a margarina, o coração é apenas órgão de consumo. A partir do alto modernismo da poesia portuguesa, não mais se retrata o poeta sem que o fingimento, ou seja, a ação ou o efeito de esculpir esteticamente, participe do jogo. A última palavra, grafei-a para citar a estrofe de "Autopsicografia" que ora me interessa: "E assim nas calhas de roda/ Gira, a entreter a razão/ Este comboio de corda/ Que se chama o coração" (PESSOA, 1993, p. 104). Se o "comboio" é de brinquedo, a tarefa é lúdica. Dentro do jogo, um chamado ao "coração", palavra que, palavra sendo, indicia o símbolo ocidental do sentimento e o fato de a natureza da arte poética ser a linguagem. Sem querer insistir no falso clichê de que a Pessoa não interessa o que há de político no real circundante (que se leia "[Ela canta, pobre ceifeira]", do ortônimo, o "Opiário", de Álvaro de Campos etc.), considero proveitoso pensar em algo que Jorge de Sena (1961), imenso poeta e leitor de poesia, escreveu:

[...] à poesia, melhor que a qualquer outra forma de comunicação, cabe, mais que compreender o mundo, transformá-lo. Se a poesia é, acima de tudo, nas relações do poeta consigo mesmo e com os seus leitores, uma educação, é também, nas relações do poeta com o que transforma em poesia, e com o acto de transformar e com a própria transformação efectuada - o poema -, uma actividade revolucionária. Se o "fingimento" é, sem dúvida, a mais alta forma de educação, de libertação e de esclarecimento do espírito enquanto educador de si próprio e dos outros, o "testemunho" é, na sua expectação, na sua discrição, na sua vigilância, a mais alta forma de transformação do mundo, porque nele, com ele e através dele, que é antes de mais linguagem, se processa a remodelação dos esquemas feitos, das ideias aceites, dos hábitos sociais inscientemente vividos, dos sentimentos convencionalmente aferidos. (SENA, 1961, p. 11)

Datado de março de 1960, o prefácio à primeira reunião do Sena poeta contribui para uma revisão de Pessoa e para que um novo 
alicerce, o "testemunho", seja posto sob a construção da poesia portuguesa contemporânea. Noto ali, no viés mais diretamente político que o texto possui, uma herança do Manifesto do partido comunista, onde se lê da efetiva transformação do mundo, por exemplo, no apoio a "qualquer movimento revolucionário contra a ordem social e política vigente" (MARX; ENGELS, 2006, p. 120), e Sena (1961) sempre foi atento a Marx. O que me importa mais, contudo, é ler um seniano Manuel de Freitas tendo que articular "fingimento" e "testemunho", prática que, aliás, foi realizada por Sena (1961), por Pessoa (1993) e, com o perdão do exagero, por toda poesia dotada de alguma ética.

Assim, o poeta que diz para poucos, poeta que gostaria, sem o poder, de "compreender o mundo" e "transformá-lo", testemunha uma propaganda de televisão na qual localiza uma espécie de barbárie. Sena, noutro tempo, escreveu um testamento contra a barbárie intitulado "Carta a meus filhos sobre os Fuzilamentos de Goya"; venho dizendo que à poesia portuguesa recente apresenta-se, mais que a qualquer outra, o pequeno, e insisto nisso agora. Expresso com clareza também dois aspectos que podem ter passado despercebidos nos parágrafos acima: "coração" é palavra-chave do poema pessoano que mais de perto tratou de fingimento; Manuel de Freitas (2005) tem Pessoa em perspectiva, como qualquer português a escrever após o Modernismo, mas um dos poetas de sua eleição é Sena, como fica evidente, por exemplo, no título de seu livro de 2007, Terra sem coroa, direta homenagem em revisão a título de um Sena ainda jovem, Coroa da terra.

O "testemunho", pois, é de um "Spot": e o "fingimento"? A parte de Game over a que pertence o poema intitula-se "Depois do fim", e é como se os projetos de Pessoa, Sena e tantos outros não mais fossem possíveis. O coração talvez seja impossível, impossível até o "coração" como palavra de poema, enquanto os receptores supostos do comercial são "não-cardíacos". Hipótese 1: a margarina Becel baseia suas campanhas publicitárias no benefício que esse produto traz ao coração humano; numa 
sociedade neurótica, os "não-cardíacos" que compram o produto, comprando sua autoconferida fama, enxergam-se como cardíacos potenciais, demonstrando o velho medo da morte de maneira atualizadamente direcionada. Hipótese 2: "não-cardíacos" são os espectadores da propaganda, e a linguagem poética, "comboio de corda", depara-se, numa sociedade como a nossa, com "nãocardíacos" num nível metafórico: o não-coração pertence a um não-poema; consequentemente, não-leitores recebem-no, e eles são indivíduos aos quais é vedado desenvolver uma sensação de caráter cardíaco, pois não passam da percepção da víscera mortal, ignorando que há um trabalho poético com o símbolo. A publicidade procura construir uma estética, portanto um campo de afetos, de recepção imediata e rápida, mas cheia de segundas, terceiras e quartas intenções subliminares. "A alienação do espectador em favor do objeto contemplado", segundo o ainda vigorante e vigoroso Debord (1997, p.24),

se expressa assim: quanto mais ele contempla, menos vive; quanto mais aceita reconhecer-se nas imagens dominantes da necessidade, menos compreende sua própria existência e seu próprio desejo. Em relação ao homem que age, a exterioridade do espetáculo aparece no fato de seus próprios gestos já não serem seus, mas de um outro que os representa por ele. É por isso que o espectador não se sente em casa em lugar algum, pois o espetáculo está em toda parte.

assim como os televisores nos dias atuais, janelas de espetacular e viciante onipresença. Se "quem não sabe arte, não na estima”, como saber "arte" numa sociedade dominada por um tipo de indivíduo que sequer responde por "sua própria existência e seu próprio desejo", já que começa a se esquecer de relações como a que existe entre desejo, escolha e ética? O "espectador não se sente em casa em lugar algum", dado que a noção de cidade, res publica, sofreu uma transformação extrema. Décadas nos separam da publicação de $A$ sociedade do espetáculo, e algo certamente se modificou desde então; a onipresença da linguagem publicitária tal como hoje se apresenta é uma das novidades. Se comparo o excerto 
do pensador francês, recém-transcrito, a um comentário bastante recente, encontrado numa revista de negócios editada em fins de 2009, a surpresa beira a estupefação. Martin Lindstrom, teórico de um espantoso novo ramo científico chamado neuromarketing, é entrevistado; uma de suas afirmações: posto que "[...] 85\% de todas as decisões que tomamos [...] acontecem em nossa mente não consciente", "propaganda subliminar funciona". Não basta, segue o entrevistado: "[...] existe um forte paralelo entre o mundo da religião e o mundo do branding ${ }^{4}$. [...] as marcas do futuro irão começar a se inspirar no mundo da religião" (LINDSTROM, 2009, p. 152).

Privatizado está o público, privatizado e em estado potencialmente comercial o religioso. Não é tanto a velha riqueza monumental das religiões, nem as vendas de objetos com remissão sagrada, caros ou não, às portas das igrejas. As "marcas do futuro irão começar a se inspirar no mundo da religião", mas diversas religiões do presente já se baseiam em estratégias comercias, haja vista o neoevangelismo tão em voga ao nosso redor. A história da Igreja Católica pode ser mera inspiração embrionária para um tipo de investimento que pode ser visto como uma nova Cruzada; agora, a invasão é, já disse eu, pretensamente afetiva, no limite, sacralizada, sem que a sagração impeça a compra,

${ }^{4} \mathrm{O}$ leitor deste texto, em virtude de sua formação, talvez não saiba o que é "branding". Tampouco eu o sei. Portanto, recorro à Wikipédia, onde leio, entre outras coisas, que branding é "o trabalho de construção e gerenciamento de uma marca junto ao mercado. A construção de uma marca forte para um produto, uma linha de produtos ou serviços é consequência de um relacionamento satisfatório com o mercado-alvo. Quando esta identificação positiva se torna forte o bastante, a marca passa a valer mais do que o próprio produto oferecido. Branding é como é chamado o conjunto de práticas e técnicas que visam a construção e o fortalecimento de uma marca" (http://pt.wikipedia.org/wiki/ Branding, acesso a 27 de março de 2013). Fico atento: "a marca passa a valer mais do que o próprio produto oferecido". Não me espanta que algo seja maior do que ele mesmo, mas uma marca ser o excedente do produto me soa como se um produto fosse mais do que seu valor de uso, seu fetiche e sua simbologia social. Seria a marca a alma do produto? Se for, produtos têm alma. Isso não é coisa pouca. 
pelo contrário. Permito-me uma hipérbole, se é que cometo uma hipérbole: no universo das religiões, os sacerdotes intermedeiam a relação entre o crente e o sobrenatural; se alguém, no atual estágio do capitalismo, descrito por Bauman como sociedade de consumidores, faz a intermediação entre comprador e compra, é o publicitário, cuja empresa é encher de desejo um bem material. Estou sugerindo que o publicitário foi alçado a uma posição sacerdotal (eis a hipérbole), e a compra, em ato sagrado, mas ao alcance de hebreus e gentios: há uma perversa democracia nesses templos.

O cenário que se apresenta alarma até mesmo alguém como Lindstrom (2009, p. 152), que diz noutro momento da entrevista: "Os comerciais de TV irão, esperamos, tornar-se mais atraentes e o merchandising, mais relevante - mas talvez mais assustador. Existe uma chance de que o marketing comece a ir para o subterrâneo [...], a apelar à nossa mente não consciente". (A consequência: "[...] o consumidor" será posto "em uma situação na qual ele tem pouco a dizer" (LINDSTROM, p. 153). Manuel de Freitas o sabe: o mundo está cheio de consumidores "não-cardíacos", não de cardíacos cidadãos; mais: o indivíduo já tem pouco a dizer, o poeta, o feminino, o coração que encerra um poema fundamental; quem "diz"? A "margarina becel".

Os neuróticos "não-cardíacos" se encontram numa sociedade, além de tudo, esquizofrênica. É bom e vendável um coração sadio, mas é prazeroso autodestruir-se em lanchonetes de comida supercalórica e gordurosa. Há clara biunivocidade entre autodestruição e cuidado com a saúde: ambos vendem e, já que seu oposto voga, ambos vendem mais. Além disso, os produtos ditos saudáveis são, em geral, mais caros, o que torna um lado da moeda recém-comentada bastante dispendioso: “A vida está cada vez mais cara" (JORGE, 2001, p. 154), escreveu a sempre bemvinda, e mais uma vez vinda a este ensaio, Luiza Neto Jorge, e já tive a chance de abordar, pelo viés de algumas carestias, o poema luiziano cujo primeiro verso citei ${ }^{5}$.

${ }^{5}$ Refiro-me ao meu ensaio "Luiza está cada vez mais cara", presente no livro, 
De todo modo, a publicidade que impele o indivíduo a comer verdadeiras bombas em nada saudáveis obriga-o a ser magro. Debord (1997) : "quanto mais" a pessoa "aceita reconhecer-se nas imagens dominantes da necessidade, menos compreende sua própria existência e seu próprio desejo". Viceja um desaprendizado do gosto, pois uma alienação do desejo. Insinuei uma sutil diferença entre o tempo de Debord e o nosso, e ela é claramente perceptível nas palavras de Martim Lindstrom (2009): dizer, outrora, da alienação do indivíduo em relação a si próprio era um escândalo cheio de assombrosa novidade; presentemente, é uma constatação, ainda assustadora, mas nem tanto, e em época de política frouxa, aceita-se o inaceitável de modo apenas desconfortável, um pouco atemorizado, mas nem tanto.

A denúncia que me leva a esta reflexão é feita por um poeta, e comecei a pensá-la com Platão. É sabido que quem faz versos de modo imitador deve ser expulso da cidade, já que, assim como o pintor, produz "apenas obras sem valor do ponto de vista da verdade" (PLATÃO, 2006, Rep 605 a), e o "mais grave dos" "malefícios" da "poesia" é ser "capaz de corromper até as pessoas honestas" (PLATÃO, 2006, Rep 605 c). Por outro lado, "[...] se a poesia imitativa, voltada para o prazer, pode provarnos com boas razões que ela tem o seu lugar numa cidade bem ordenada, recebê-la-emos com grande júbilo" (PLATÃO, 2006, Rep 607 c). É a justiça na res publica o que procura um impositivo Sócrates, e penso no que ele diria caso se deparasse com nossas cidades tomadas por anúncios publicitários, e quais seriam seus indexadores de justiça. A personagem platônica salienta o poder atrativo que se encontra na poesia - "[...] temos consciência da sedução que ela exerce sobre todos nós [...] (PLATÃO, 2006, Rp 607 c)" -, o que, certamente, não ocorre numa sociedade espetacular, a não ser quando algo vagamente semelhante à poesia salienta a circunstância e não o texto, o entorno e não o dentro, as criaturas e não os versos...

organizado por Ida Alves. Um corpo inenarrável e outras vozes: estudos de poesia portuguesa moderna e contemporânea. Nitéroi: Editora da UFF, 2010. 
Portanto, é atualmente desnecessário expulsar o poeta da res publica (grifo nosso), pois à margem dela ele já está, e há muito tempo: o primeiro grande leitor de Cesário Verde, Álvaro de Campos, heterônimo de "fingimento" e "testemunho" - ficcional, decerto, mas que "testemunho" em "linguagem", palavra grafada por Sena, não o será? -, é autor dos seguintes versos, em "Lisbon revisited (1923)": "Não me peguem no braço!/ Não gosto que me peguem no braço!/ Já disse que sou só sozinho!/ Ah, que maçada quererem que eu seja de companhia!" (PESSOA, 1999, p. 137). Sendo Campos um engenheiro, e tendo, tanto Bernardo Soares como, biograficamente, Fernando Pessoa, empregos, não me parece disparatado supor esses versos como o rascunho da condição do poeta "vil, literalmente vil" (PESSOA, 1999, p. 235) - como se lê no "Poema em linha reta" -, ou seja, de valor baixo: está ele "só sozinho" porque não é "de companhia" nem de Companhia (ou Corporation) alguma.

Que resta ao poeta diante da metonímia que é o "Spot" da "margarina becel", detentor do "horário", porque mais caro à publicidade, "nobre"? Sentir "saudades da censura", numa fala de alta periculosidade, pois se encontra o sujeito em Portugal, país com memória recente e dolorosa da censura salazarista. No entanto, ambicionada é "uma censura nova", que estaria para a cidade privatizada como Sócrates está para sua projetada res publica. Cito mais uma vez a estrofe final do poema: "O que, na verdade, me/ deixa saudades da censura,/ de uma censura nova/ que exterminasse imbecis/ e deixasse a terra a quem/ ela é, como deve ser, pesada." (PESSOA, 1993). Não o filósofo, mas o poeta vilipendiado é quem decretará o extermínio de "imbecis"

${ }^{6}$ Ao ler este texto em caráter inédito, Jorge Fernandes da Silveira, não perdendo
a piada, forjou o vocábulo imbeceis. Não há, em verdade, piada alguma (exceto,
claro, no bom sentido português): para além de a palavra nova aproximar um
dos adjetivos centrais do poema ao nome da margarina, imbeceis sabe-me
plural possível para a construção In Becel, que supõe uma enorme gama de
"não-cardíacos" dentro (in) do produto. Ou seja, indivíduos são engolidos por
um bem construído branding e uma publicidade exitosa. A propósito, como fiquei curioso acerca do nome Becel, fui ao sítio de internet 
e frondosas alienações, resguardando seus semelhantes do poder da publicidade, ela sim "capaz de corromper até as pessoas honestas". É evidente que existe ironia no discurso do poema, pois quem o emite não tem a menor condição de gerar qualquer extermínio, pois é poeta, e já está explícito que tipo de poder de fogo os poetas têm.

Irônico também é o encerramento de outro poema de Freitas, intitulado "Escudos humanos": "A guerra já está ganha,/ a morte é garantida e um poema,/ infelizmente, não é uma arma química." (FREITAS, 2005, p. 16). No jogo de forças que se apresenta em nossa contemporaneidade, Freitas emite um discurso que, além de pequeno, aponta para fora de si, vendo nisso um modo de fazer política. Segundo Pedro Eiras (2011, p.32), a "contemporaneidade [...] parece-me [...] uma lição mais política que ontológica; se o mundo se converteu em mercadoria, o poema interroga - sabendo-se ele próprio mercadoria - as coisas, o acesso às coisas, o direito de uso e de posse das coisas". Caso seja mesmo "ele próprio mercadoria", coisa de que não estou bem certo, é mercadoria interrogativa, inquieta, antimercantil. Como não têm força como a têm as mercadorias, poemas como "Spot" e "Escudos humanos" desejariam possui outra natureza, essa poderosa, ameaçadora: um queria ser "censura", outro, "arma química".

Não obstante sua ironia e seu reconhecimento de pouca força, o poema acorda-se com Sena, pois se ergue como "actividade revolucionária", em radical desacordo com o estabelecido e faminto por uma mudança, ainda que esta seja, em rigor, impossível - mesmo no poema, o investimento é numa quimera, a "censura nova”. Também segundo Sena (1961), “a poesia" é uma especial "educação", e qualquer tarefa educativa exige do educando uma abertura. Entre as lições que a poesia

brasileiro do produto e lá encontrei a seguinte explicação: "O nome vem da idéia original do projeto da Unilever, "Blood Cholesterol Lowering" - ou redução do nível de colesterol no sangue" (www.becel.com.br, acesso a 24 de maio de 2010). 
pode ensinar está a de que "a terra" "é, como deve ser, pesada", pois só à experiência pós-túmulo pode augurar-se, como faziam os romanos, que seja leve. Em vida, um dos aliados da publicidade é o vão contentamento coletivo, portador de uma violência que Maria Rita Kehl (2004, p. 62) comenta com argúcia:

A publicidade convoca todos a gozar de privilégios dos consumidores da elite. Se a alternativa fosse acessível a todos, não haveria privilegiados. Como não é, o que está sendo oferecido como tentação irrecusável é o direito de excluir a maioria. Assim sendo, a lógica da publicidade, hoje, está visceralmente comprometida com a lógica da violência banal que se expande como epidemia no mundo contemporâneo.

Há "privilegiados" e "maioria" excluída num mundo em que a "vida não pode ser assim/ tão assustadora". O problema é que "assustadora" a vida sempre será para os que sabem ter ela um fim, consuma-se ou não esta ou aquela margarina, este ou aquele eletrônico, este ou aquele espetáculo. A violência do poema, reativa, só revela o quanto Maria Rita Kehl (2004) tem razão ao apontar a "violência banal que se expande como epidemia no mundo contemporâneo", com a qual a "lógica da publicidade, hoje, está visceralmente comprometida". O poeta, dotado de limitada capacidade confrontativa, quase nula, no macrouniverso da sociedade de consumo, chama para si, pela indignação, uma força a todos os títulos fingida, e não deixa de convocar uma coletividade, ainda que fantasmagórica. A referência à "censura" tem uma triste possibilidade de entendimento: em épocas ditatoriais, há contra quem se lutar de modo evidente; em épocas de ditaduras brancas, o inimigo é mais insidioso e muito menos enfrentável.

Muito mais assustador do que qualquer censura é notar quem, hoje, exerce a função de censor em nossas aparentes democracias. Exemplo brasileiro: quem estabelece limites e parâmetros para a publicidade é um órgão de nome CONAR, sigla de Conselho Nacional de Autorregulamentação Publicitária. No sítio do organismo, leio: "[...] o Conar revela-se um tribunal capaz 
de assimilar as evoluções da sociedade, refletir-lhe os avanços, as particularidades, as nuanças locais. Não é [...] uma entidade conservadora, nem poderia, pois publicidade e conservadorismo [...] não combinam." (www.conar.org.br ${ }^{7}$ ). A “publicidade", então, combina com que ideia de progressismo ou vanguardismo? Com que dinâmica de cidade, de res publica? Como "um tribunal" interno, interessado em sua própria preservação, pode representar interesses que lhe são, muitas vezes, exógenos? Que cidadão sobrevive para além do consumidor? Neste ensaio, muitos autores inovaram profundamente a arte de que são mestres. Para um leitor de todos eles, não é óbvio ler associação apressada entre publicidade e inovação, palavra que aponta para o contrário de conservadorismo. Por outro lado, que tipo de conserva se está perdendo nas propagandas a que somos expostos? A fome de novidade, em nada semelhante, enfim, a inovação, engole tudo?

Tem toda a razão Camões: “[...] quem não sabe arte, não na estima”. Dizer isso hoje é dizê-lo com alguns séculos a mais de angústia; dizer isso hoje é saber que as estimas têm andado, se tem razão Manuel de Freitas, deveras "imbecis". Dizer isso hoje leva este texto, começado com Platão, a encerrar-se com a íntegra de um magnífico poema de Fiama Hasse Pais Brandão (2006), que sugere a urgência de uma nova perspectiva de "cidade" e sugere a urgência da construção de uma nova sabedoria. Começá-la por versos pode ser um excelente começo:

\footnotetext{
"Como se explica, Hípias, que os antigos sábios todos se tenham afastado dos negócios públicos?"* perguntei, porque também eu calei a minha voz pública de outrora. Cidade, perdoa-me a ausência e o rancor, perdoa que a minha voz agora não nomeie os teus cais de embarque, a dor, miséria e cúpida opressão. Ainda amo, neste exílio de paz, a mesma Paz. Sábia, não sou. Calei-me porque as memórias minhas e a voz sozinha
}

${ }^{7}$ Acesso a 28 de maio de 2010. 
também pertencem ao Todo, em harmonia.

Ainda amo a pátria, feita de lugares, parentes,

dos próximos, e do vento, meu semelhante.

* Platão, Hípias Maior. (BRANDÃO, p. 2006, p. 612)

\section{REFERÊNCIAS}

BENJAMIN, Walter. Charles Baudelaire: um lírico no auge do capitalismo. Tradução de José Carlos Martins Barbosa e Hemerson Alves Baptista. São Paulo: Brasiliense, 1989.

BRANDÃO, Fiama Hasse Pais. Obra breve. Lisboa: Assírio \& Alvim, 2006.

BUCCI, Eugênio. A crítica de televisão. In BUCCI, Eugênio; KEHL, Maria Rita. Videologias: ensaios sobre televisão. São Paulo: Boitempo, 2004. p. 27-42.

CAMÕES, Luís de. Os Lusíadas. Edição organizada por Emanuel Paulo Ramos. Porto: Porto editora, 1978.

CHAUÍ, Marilena. Convite à filosofia. São Paulo: Ática, 2001.

DEBORD, Guy. A sociedade do espetáculo: Comentários sobre a sociedade do espetáculo. Tradução de Estela dos Santos Abreu. Rio de Janeiro: Contraponto, 1997.

EIRAS, Pedro. Um certo pudor tardio: ensaio sobre os poetas sem qualidades. Porto: Afrontamento: ILC Margarida Losa, 2011.

FREITAS, Manuel de. A flor dos terramotos. Lisboa: Averno, 2005.

. Portugal, 0, 1: poemas de Manuel de Freitas. Edição, seleção e curadoria da coleção de Luis Maffei. Rio de Janeiro: Oficina Raquel, 2007.

HARVEY, David. A produção capitalista do espaço. 2. ed. Tradução de Carlos Szlak. São Paulo: Annablume, 2006.

HELDER, Herberto. Os passos em volta. 2. ed. Rio de Janeiro: Azougue, 2010. 
JORGE, Luiza Neto. Poesia. 2. ed. Organização e prefácio de Fernando Cabral Martins. Lisboa: Assírio \& Alvim, 2001.

KEHL, Maria Rita. O espetáculo como meio de subjetivação. In BUCCI, Eugênio; KEHL, Maria Rita. Videologias: ensaios sobre televisão. São Paulo: Boitempo, 2004. p. 43-62.

LINDSTROM, Martin. A missão é investigar o cérebro: entrevista com Martin Lindstrom. Revista Época Negócios n. 32. São Paulo: Editora Globo, out.2009. p. 150-153.

MARX, Karl Heinrich; ENGELS, Friedrich. Manifesto do Partido Comunista. São Paulo: Global, 2006.

PESSOA, Fernando. O Eu profundo e os outros eus. 22. ed. Seleção de Afrânio Coutinho. Fixação dos textos e notas de Maria Aliete Galhoz. Rio de Janeiro: Nova Fronteira, 1993.

- Poemas de Álvaro de Campos. Edição de Cleonice Berardinelli. Rio de Janeiro: Nova Fronteira, 1999.

PLATÃO. A República. Organização e tradução de J. Guinsburg. São Paulo: Perspectiva, 2006.

SENA, Jorge de. Poesia: 1. Lisboa: Morais, 1961.

Recebido em 30/03/2013.

Aprovado em 17/10/2013. 